\title{
Indústria e crescimento econômico: evidências para países desenvolvidos e em desenvolvimento
}

\author{
FLÁVIO VILELA VIEIRA \\ ANA PAULA AVELLAR \\ MICHELE POLLINE VERÍSSIMO*
}

Industry and economic growth.

The work develops an empirical investigation on the relevance of industry / GDP, manufacture / GDP and industrial employment / total employment on long run growth using panel data. The results indicate the existence of a direct and significant relation for industry (manufacture) share to GDP and industrial employment for long run growth. The annual impact on growth of a $10 \%$ increase, over a five year period, in the industry share to GDP (manufacture share to GDP) ranges from $0.19 \%$ to $0.32 \%(0.2 \%$ to $0.4 \%)$ and for the industrial employment / total employment it varies from $0.3 \%$ to $0.5 \%$.

Keywords: industry and manufacture share to GDP; industrial employment; economic growth; panel data analysis.

JEL Classification: O40; L16; C23.

\section{INTRODUÇÃO}

O objetivo deste trabalho é investigar empiricamente, através da análise de painel para um conjunto de 82 economias desenvolvidas e em desenvolvimento, a relação entre a participação da indústria, do setor manufatureiro na economia e do emprego industrial, sobre o crescimento econômico nas últimas quatro décadas, controlando também para variáveis já consagradas na literatura teórica e empírica

\footnotetext{
* Professor do Instituto de Economia - UFU, Pesquisador CNPq e FAPEMIG. E-mail: flaviovieira@ufu. br; Professora do Instituto de Economia - UFU, Pesquisadora CNPq e FAPEMIG. E-mail: anaavellar@ ie.ufu.br; Professora do Instituto de Economia - UFU, E-mail: michele@ie.ufu.br. Submetido: 30/ agosto/2012; Aprovado: 21/outubro/2013.
} 
sobre crescimento (nível de renda per capita, inflação, gastos do governo, instituições e capital humano).

Uma parte da literatura sobre crescimento econômico sugere a existência de efeitos favoráveis que o setor industrial e sua participação relativa na economia pode exercer em termos da dinâmica de crescimento nas diversas economias quando comparada aos demais setores (agricultura e serviços), sendo que tais efeitos estão associados a questões como maior dinâmica de incorporação dos avanços tecnológicos e inovações, ganhos de produtividade, maior remuneração dos fatores de produção (capital e trabalho), efeitos de transbordamento (spillovers), dentre outros. Neste sentido, justifica-se uma análise que possa utilizar alguns indicadores específicos do setor industrial nas diversas economias no intuito de examinar uma possível relação entre tais indicadores e o crescimento econômico.

A elaboração deste trabalho visa contribuir para o debate acadêmico e político mais recente associado à existência ou não de um processo de desindustrialização que tem afetado diversas economias emergentes, Brasil incluído, em um contexto marcado por recorrentes períodos de apreciação da taxa de câmbio real e suas consequências sobre a competitividade e dinâmica do setor industrial.

A investigação empírica será desenvolvida através da estimação de modelos de crescimento com dados em painel utilizando a metodologia System GMM que incorpora a presença da variável dependente (taxa de crescimento econômico) defasada dentre as variáveis explicativas, sendo que são utilizados nas estimações dados com médias quinquenais, para o período de 1970 a 2009, com exceção da variável renda per capita, em que se utiliza dados do início do quinquênio.

A estrutura do trabalho é composta por três seções, além das considerações finais. A primeira seção sistematiza uma revisão da literatura sobre indústria e crescimento econômico, enquanto a segunda desenvolve um panorama evolutivo através da comparação de indicadores industriais para economias e regiões selecionadas. A terceira seção se dedica a uma breve apresentação da metodologia de estimação de modelos em painel e à análise dos resultados econométricos.

\section{INDÚSTRIA E CRESCIMENTO ECONÔMICO: REVISÃO DA LITERATURA}

A estrutura produtiva pode ser considerada um fator relevante na determinação do crescimento econômico de um país. A literatura sobre a importância do setor industrial na dinâmica do crescimento econômico, ainda que não exclusivamente associada aos trabalhos clássicos dos modelos de crescimento (Solow, 1956), passou a ser desenvolvida quase que simultaneamente com os trabalhos de Chenery e Watanabe (1958) e Chenery (1960).

O segundo desses trabalhos analisa os padrões de crescimento industrial e deixa claro que um aumento no nível de renda per capita de um país, como indicador de um maior desenvolvimento econômico, está associado a um aumento na participação do setor industrial na produção agregada (PIB): 
An increase in per capita income in a country is normally accompanied by a rise in the share of industrial output. The accepted explanation for this relationship is the change in the composition of demand, of which the decline in the share of food (Engel's Law) is the most notable feature. However, this overall relationship does not necessarily apply to every individual country. Within limits, the changing composition of domestic demand can be offset through foreign trade. (Chenery, 1960, p. 624)

Chenery (1960) destaca ainda que as maiores variações nos níveis de produto ocorrem nas indústrias de maquinaria, equipamentos de transporte e bens intermediários, onde o papel das economias de escala é mais importante, enquanto as diferenças na dotação dos fatores de produção se refletem principalmente através das mudanças nas proporções dos bens produzidos domesticamente e importados nos diversos setores. Uma das conclusões finais do autor é a de que há uma maior probabilidade de que os setores líderes estejam associados aos setores industriais onde a substituição das importações se tornaram mais rentáveis com a expansão dos mercados, processo este acompanhado pela aquisição de capital e habilidades.

O debate sobre crescimento econômico é também apresentado por outra perspectiva teórica por meio dos modelos de crescimento de Kaldor $(1957,1966)$. O referido autor desenvolve um conjunto de pressupostos que enfatizam o papel do crescimento da atividade manufatureira para o crescimento econômico (primeira lei) e a relação entre o produto e a produtividade do trabalho na manufatura derivada dos retornos crescentes de escala dinâmicos e estáticos (segunda lei, também conhecida como Lei de Verdoon). Partindo desse referencial teórico, Libânio e Soro (2009) analisam o crescimento dos países da América Latina para testar as leis de Kaldor. O trabalho realiza uma análise de painel (efeitos fixos) para as 11 maiores economias da América Latina no período 1980-2006. Os resultados apontam que um impacto positivo do crescimento da manufatura sobre o crescimento econômico pode estar relacionado à transferência de trabalho dos setores de baixa produtividade para os setores de produtividade mais elevada. As evidências também indicam a existência de significativos retornos de escala na manufatura, sendo que, quando o estoque de capital é tratado como exógeno nas estimativas, verifica-se que o aumento da produtividade parece responder positivamente ao aumento do crescimento do produto no setor manufatureiro. Portanto, os resultados indicam a possibilidade de ciclos cumulativos de crescimento naquelas economias baseados na expansão das atividades industriais, mas, para isso, é importante ter cuidado com a tendência de aumento da participação de commodities e bens intermediários nas exportações na região e o declínio nas exportações de manufaturas (desindustrialização) devido aos efeitos potenciais negativos sobre o crescimento no longo prazo.

Com intuito de compreender a relação entre indústria e crescimento econômico em países em desenvolvimento, alguns estudos como o de Baer (1972) avaliam diversas estratégias de industrialização por substituição de importações (ISI) para países da América Latina. Esse autor destaca que, nos anos 1950 e 1960, a justificativa para a adoção das estratégias de ISI estava associada à ideia de elevar a taxa 
de crescimento econômico e de modernização socioeconômica. Nos anos 1970, as evidências indicam que, com o processo de urbanização, essas economias passaram a vivenciar redução na taxa de crescimento industrial, além de problemas de elevados custos de produção dos bens industriais que limitavam a capacidade de exportar tais bens. Os principais instrumentos de política para promover os processos de ISI envolveram tarifas, controles cambiais, regimes de preferência para importação de bens de capital para novas indústrias e empréstimos subsidiados por parte do governo para indústrias selecionadas. A análise dos dados para os anos 1960 revela que a indústria passou a ser o setor dominante (participação no PIB) para Argentina, Brasil, México e Chile, sendo que as taxas de crescimento industrial na América Latina nas décadas de 1940, 1950 e 1960 ficaram acima daquelas verificadas para a economia como um todo (Baer, 1972, p. 101).

Alguns estudos empíricos vêm sendo desenvolvidos desde o início dos anos 1990 com objetivo de investigar a relação entre indústria e crescimento. De Long e Summers (1991) investigam a relação existente entre investimento em equipamentos / maquinaria e crescimento econômico para o período de 1960 a 1985. Os resultados indicam uma relação robusta e positiva entre investimento em equipamentos / maquinaria e crescimento econômico, sendo que as estimativas são de que, para cada $1 \%$ do PIB investido em equipamentos e maquinarias, há um aumento de $0,33 \%$ ao ano no PIB.

Pieper (1998), por sua vez, desenvolve um estudo empírico sobre a relação indústria, emprego e produtividade a partir de um conjunto de países em desenvolvimento. A análise envolve o período de 1975 a 1993 e encontra evidências sobre a existência de uma relação positiva entre o desempenho industrial e o desempenho econômico global, a geração de emprego e o crescimento da produtividade.

Estudos desenvolvidos pela Cepal (Cepal, 2008; Abelles \$ Rivas, 2010) ressaltam que os países que avançaram economicamente nas últimas décadas possuem estrutura industrial diversificada, voltada para atividades econômicas intensivas em progresso técnico. Consideram, assim, que uma explicação para a redução da renda per capita dos países latino-americanos em relação aos países mais avançados encontra-se na estrutura produtiva, em que prevalecem setores intensivos em recursos naturais e baixa intensidade inovativa. Abelles e Rivas (2010), com base em evidências empíricas, concluem ainda que, para ocorrer a convergência das economias latino-americanas com as avançadas, será necessário um processo de intensificação da industrialização.

Uma literatura mais recente (Gala, 2008; Berg \& Miao, 2010; Rodrik, 2008; Vieira \& MacDonald, 2012) tem investigado o papel da taxa de câmbio e do desalinhamento cambial sobre o crescimento econômico. Gala (2008) ressalta a importância de se analisar dois importantes canais através dos quais o nível da taxa de câmbio afeta o crescimento, ou seja, através de mudanças no investimento e na tecnologia. A ideia central é que ao afetar os salários reais, a taxa de câmbio influencia a poupança agregada, os investimentos e a dinâmica da dívida externa. Taxas de câmbio sobrevalorizadas exercem efeitos de redução na taxa de lucro do setor de bens comercializáveis que frequentemente reduzem as taxas de investimen- 
to, enquanto taxas de câmbio subvalorizadas estão associadas a preços mais elevados dos bens comercializáveis, menores níveis de salários reais, e maiores margens de lucro e taxas de investimentos. $\mathrm{O}$ argumento é que, com respostas elásticas das exportações e dos investimentos, a taxa de câmbio mais depreciada tem um papel importante de estimular o crescimento econômico através de um padrão liderado pelo investimento ${ }^{1}$. Esse autor destaca ainda que a manutenção de taxas de câmbio competitivas contribui para a acumulação de capital ao estimular o investimento, e do ponto de vista tecnológico é capaz de estimular o desenvolvimento de setores não tradicionais de comercializáveis, permitindo elevações de salário real que podem compensar efeitos negativos de uma moeda mais depreciada para os trabalhadores.

Rodrik (2008) analisa a relação entre desalinhamento cambial e crescimento para um conjunto de 184 países com dados de 1950 a 2004, utilizando um índice para medir o grau de subvalorização cambial ajustada ao efeito Balassa-Samuelson. O principal resultado empírico encontrado é que o crescimento é maior em países com taxa de câmbio real mais depreciada enquanto taxas de câmbio mais valorizadas estão associadas a menores taxas de crescimento. Além disso, esse autor destaca que a magnitude e a significância estatística dos coeficientes estimados para o grau de subvalorização (UNDERVAL) cambial, proxy para o desalinhamento cambial, é maior em países em desenvolvimento devido a características de fragilidade institucional e falhas de mercado. Berg e Miao (2010) desenvolvem uma investigação empírica sobre o desalinhamento da taxa de câmbio real para comparar os resultados obtidos por Rodrik (2008) com o que chama de visão do Consenso de Washington (WC), que é baseada no chamado modelo de equilíbrio fundamental da taxa de câmbio (FEER). Os resultados corroboram aqueles encontrados por Rodrik (2008) quanto aos benefícios (malefícios) para o crescimento econômico de uma taxa de câmbio mais depreciada (apreciada). Esses autores sugerem ainda que, ao se separar os chamados efeitos diretos e indiretos dos fatores que explicam o crescimento econômico, há evidência favorável à chamada visão WC².

Rodrik (2009) investiga o crescimento das economias em desenvolvimento a partir da hipótese de que maiores taxas de crescimento econômico estão atreladas aos avanços dos setores de bens comercializáveis e outros produtos não primários. Esse autor argumenta que a obtenção de taxas de crescimento sustentadas, como no Japão, Coreia do Sul e China, se encontra baseada no desenvolvimento das capa-

\footnotetext{
${ }^{1}$ Uma discussão subjacente com interesse à discussão do presente artigo diz respeito ao fato de que apreciações significativas da taxa de câmbio afetam de maneira expressiva a rentabilidade dos investimentos no setor manufatureiro já que este é um setor com alta participação de bens comercializáveis.

${ }^{2}$ Vieira e MacDonald (2012) utilizam outras variáveis além do efeito Balassa-Samuelson para calcular a taxa de câmbio de equilíbrio e obter sete medidas de desalinhamento cambial, além de utilizar técnicas de cointegração em painel para calcular duas medidas adicionais de desalinhamento cambial. Os resultados empíricos corroboram as evidências já obtidas por Rodrik (2008) sobre os efeitos positivos (negativos) de uma taxa de câmbio real mais depreciada (apreciada).
} 
cidades industriais em vez da especialização na produção de bens que contam com vantagens comparativas no comércio internacional. Neste sentido, esse autor realiza uma análise de painel para investigar a associação entre indústria (medida pelo valor adicionado da indústria no PIB e participação do emprego industrial no emprego total) e taxa de crescimento econômico. Obtêm-se evidências de que a expansão da atividade industrial está associada com crescimento econômico mais rápido, e que taxas de câmbio depreciadas estão atreladas ao crescimento mais elevado, em decorrência dos seus efeitos sobre o tamanho da indústria. Estes resultados são explicados pelos gaps existentes entre a produtividade marginal social das atividades modernas e tradicionais nos países em desenvolvimento, determinados pela fraqueza institucional e dos direitos de propriedade, falhas de mercado, externalidades e efeitos de aprendizado. Sendo assim, mudanças nos fundamentos econômicos, na produtividade das atividades industriais, na transferência de recursos dos setores tradicionais para os setores industriais, e na promoção de políticas industriais ativas, contribuem para acelerar o crescimento econômico.

$\mathrm{Na}$ atualidade, um dos temas mais presentes no debate internacional busca verificar a existência do fenômeno da desindustrialização em países desenvolvidos e em desenvolvimento. Tregenna (2008) analisa a adequação da definição usual de desindustrialização como um declínio da participação da manufatura no emprego total. A análise parte da hipótese de que pode haver uma queda da participação da manufatura no emprego total em virtude de mudanças na produtividade do trabalho na indústria sem que haja necessariamente uma menor participação do setor industrial no produto total. Para isso, essa autora analisa as mudanças da participação e do nível de emprego na manufatura em 48 países em períodos de desindustrialização utilizando técnicas de decomposição desse processo em componentes associados com o aumento do valor adicionado na manufatura, com a produtividade do trabalho no setor, com a participação da manufatura no PIB e com o crescimento econômico. Os resultados indicam que a maioria dos casos de declínio do nível ou da participação do emprego no setor industrial está relacionada com a queda da intensidade do trabalho na manufatura em vez de um declínio do valor adicionado ou da participação do setor manufatureiro no PIB. Assim, Tregenna (2008) aponta a dificuldade de formular um conceito genérico de desindustrialização, pois a queda do nível ou da participação da manufatura no emprego total em decorrência da menor intensidade do trabalho na indústria não pode ser encarada como uma desindustrialização em sentido real. Nestes termos, uma definição apropriada para desindustrialização deve ser relacionada ao declínio sustentado tanto da participação da manufatura no emprego total como da participação da manufatura no PIB.

Em termos da discussão sobre desindustrialização na economia brasileira, diversos trabalhos como Bresser-Pereira e Marconi (2008), Sampaio e Pereira (2009), e Oreiro e Feijó (2010) enfatizam uma relação de perda de participação da produção industrial brasileira no PIB em função das políticas macroeconômicas adotadas na economia pós-Real, do contexto de apreciação cambial e do cenário internacional favorável aos preços dos produtos intensivos em recursos naturais verificados ao longo dos anos 2000, o que incentivou a produção e exportação de commodities em 
prejuízo dos setores industriais intensivos em tecnologia sofisticada. De modo geral, tais trabalhos observam uma relativa perda de participação do setor industrial em relação ao PIB brasileiro, e um aumento do déficit comercial dos setores produtores de bens industriais ao longo do tempo, enquanto verifica-se a sustentação dos superávits comerciais em função do bom desempenho das exportações de bens intensivos em recursos naturais. Estes fatores, em um contexto de apreciação cambial, podem vir a prejudicar o potencial de crescimento de longo prazo da economia brasileira.

\section{CRESCIMENTO E INDICADORES INDUSTRIAIS SELECIONADOS: UM PANORAMA EVOLUTIVO PARA ECONOMIAS E REGIÕES SELECIONADAS}

A presente seção do trabalho tem por objetivo realizar uma análise comparativa entre países e regiões para alguns indicadores selecionados - taxa de crescimento do PIB, participação da indústria e do setor manufatureiro no PIB, e a participação do emprego industrial no emprego total. O intuito é traçar um panorama evolutivo desses indicadores ao longo de quatro décadas (1970 a 2009) de forma a se avaliar possíveis distinções entre países e regiões em termos de crescimento econômico com referência em tais indicadores de desempenho do setor industrial e tecnológico.

A escolha dos países Argentina, Brasil, Chile, China, Índia, Coreia do Sul, México e EUA tem por objetivo, em um primeiro momento, a análise comparativa das principais economias latino-americanas e, em um segundo momento, a inclusão de duas economias emergentes (China e Índia) com destaque tanto no comércio mundial quanto em termos de seus desempenhos no crescimento econômico. Por fim, tem-se a adição de dois outros países, sendo que no caso da Coreia do Sul, esta pode ser considerada como um paradigma no sentido de que conseguiu ao longo das últimas décadas fazer a transição de uma economia em desenvolvimento para uma economia pautada em grande medida nos ganhos de eficiência produtiva associados ao avanço tecnológico na produção de vários bens, inclusive os exportados, enquanto os EUA servem como benchmark de uma economia avançada e com alto grau de desenvolvimento econômico, que é, em última instância, o objetivo último a ser alcançado.

A escolha das regiões tem por objetivo comparar a América Latina e Caribe com a região asiática (duas sub-regiões), dado que esta última pode ser considerada a região onde se encontram os países com maiores taxas de crescimento e vigoroso desempenho exportador; a União Europeia, que inclui boa parte dos países com maior grau de desenvolvimento econômico e avanços no emprego industrial; e a África Subsaariana, como representativa de uma região com menor grau de desenvolvimento e pior desempenho quando se analisam os indicadores de interesse (emprego industrial, participação da indústria e do setor manufatureiro no PIB $)^{3}$.

\footnotetext{
${ }^{3}$ A Tabela $1 \mathrm{~A}$ do Apêndice detalha os países integrantes de cada uma das regiões utilizadas na análise comparativa das Tabelas 1 a 4 .
} 
A análise comparativa das taxas de crescimento econômico entre os países selecionados nas últimas quatro décadas (Tabela 1) revela um desempenho de destaque para os países asiáticos (China, Índia e Coreia do Sul), não apenas em termos de média de crescimento variando entre $4,94 \%$ e $9,70 \%$, mas também quando comparados com a média mundial $(1,79 \%)$. O desempenho das economias latino-americanas revela que estas tiveram crescimento acima da média mundial no período, com exceção da Argentina. O crescimento econômico verificado na economia norte-americana se mostrou $1 \%$ abaixo da média mundial no período. A mesma análise quando realizada para as regiões indica um melhor desempenho relativo das duas sub-regiões asiáticas, em especial dos países da Ásia do Sul com crescimento médio de 6,01\%, bem acima da média mundial $(1,79 \%)$. A América do Sul e Caribe obteve um crescimento médio de 2,91\% no período, enquanto as economias da União Europeia revelam crescimento médio próximo da média mundial. Sumarizando, pode-se argumentar que os países e regiões asiáticos tiveram o melhor desempenho comparativo em termos de taxa de crescimento nas últimas quatro décadas.

Tabela 1: Taxa de Crescimento do PIB (\%)

\begin{tabular}{|c|c|c|c|c|c|c|c|}
\hline Países & 1970 & 1980 & 1990 & 2000 & 2009 & $\begin{array}{l}\text { Média das } \\
\text { Décadas }\end{array}$ & $\begin{array}{l}\text { Diferença da } \\
\text { Média Mundial }\end{array}$ \\
\hline Argentina & 3,05 & 4,15 & $-2,40$ & $-0,79$ & 0,85 & 0,97 & $-0,82$ \\
\hline Brasil & 8,77 & 9,11 & $-4,30$ & 4,31 & $-0,64$ & 3,45 & 1,66 \\
\hline Chile & 2,12 & 8,15 & 3,70 & 4,49 & $-1,53$ & 3,39 & 1,60 \\
\hline China & 19,40 & 7,80 & 3,80 & 8,40 & 9,10 & 9,70 & 7,91 \\
\hline Índia & 5,15 & 6,74 & 5,53 & 4,03 & 9,10 & 6,11 & 4,32 \\
\hline Coreia do Sul & 8,34 & $-1,49$ & 9,16 & 8,49 & 0,20 & 4,94 & 3,15 \\
\hline México & 6,50 & 9,23 & 5,07 & 6,60 & $-6,54$ & 4,17 & 2,38 \\
\hline Estados Unidos & & $-0,29$ & 1,86 & 4,17 & $-2,63$ & 0,78 & $-1,01$ \\
\hline Mundo & & 1,82 & 2,97 & 4,29 & $-1,93$ & 1,79 & \\
\hline Regiões & 1970 & 1980 & 1990 & 2000 & 2009 & $\begin{array}{c}\text { Média das } \\
\text { Décadas }\end{array}$ & $\begin{array}{c}\text { Diferença da } \\
\text { Média Mundial }\end{array}$ \\
\hline Ásia do Leste e Pacífico & 5,37 & 3,16 & 5,56 & 4,57 & $-0,14$ & 3,70 & 1,91 \\
\hline União Europeia & 4,70 & 1,41 & 2,75 & 3,91 & $-4,25$ & 1,71 & $-0,08$ \\
\hline América Latina e Caribe & 6,23 & 6,00 & 0,34 & 3,95 & $-1,96$ & 2,91 & 1,13 \\
\hline Ásia do Sul & 5,78 & 6,45 & 5,43 & 4,28 & 8,11 & 6,01 & 4,22 \\
\hline África Subsaariana & 7,76 & 4,03 & 1,13 & 3,69 & 1,66 & 3,65 & 1,87 \\
\hline Mundo & & 1,82 & 2,97 & 4,29 & $-1,93$ & 1,79 & \\
\hline
\end{tabular}

Fonte: WDI, 2011. 
Um dos indicadores cruciais para a investigação econométrica a ser desenvolvida na terceira seção é o valor adicionado da indústria (VAIND) ${ }^{4}$ em relação ao PIB e a Tabela 2 sistematiza a evolução comparativa ao longo das últimas quatro décadas. O destaque entre os países selecionados é a China com VAIND de 44,5\% na média do período e bem acima da média mundial (34,33\%). Outro país que se destaca neste indicador é o Chile com VAIND médio de 40,26\%, enquanto a Índia se revelou como o de pior indicador $(25,10 \%)$. Quanto às regiões, o destaque é para a Ásia do Leste e Pacífico, porém a Ásia do Sul tem o pior desempenho, enquanto a América Latina e Caribe tem VAIND similar à média mundial. O indicador de valor adicionado da indústria não tem um padrão definido em termos de regiões ou países, diferentemente da análise das taxas de crescimento, onde há uma predominância dos países e das regiões asiáticos.

Tabela 2: Valor Adicionado da Indústria - VAIND (\% do PIB)

\begin{tabular}{lccccccc}
\hline Países & 1970 & 1980 & 1990 & 2000 & 2009 & $\begin{array}{c}\text { Média das } \\
\text { Décadas }\end{array}$ & $\begin{array}{c}\text { Diferença da } \\
\text { Média Mundial }\end{array}$ \\
\hline Argentina & 42,28 & 41,22 & 36,02 & 27,61 & 31,80 & 35,79 & 1,45 \\
Brasil & 38,30 & 43,83 & 38,69 & 27,73 & 25,42 & 34,79 & 0,46 \\
Chile & 41,96 & 37,44 & 41,46 & 38,40 & 42,06 & 40,26 & 5,93 \\
China & 40,49 & 48,22 & 41,34 & 45,92 & 46,30 & 44,45 & 10,12 \\
Índia & 20,79 & 24,69 & 26,88 & 26,19 & 26,97 & 25,10 & $-9,23$ \\
Coreia do Sul & 26,02 & 36,55 & 41,57 & 38,06 & 36,52 & 35,74 & 1,41 \\
México & 32,15 & 33,65 & 28,42 & 28,02 & 34,81 & 31,41 & $-2,92$ \\
Estados Unidos & 35,24 & 33,53 & 27,86 & 23,44 & & 30,02 & $-4,31$ \\
Mundo & 38,17 & 37,09 & 33,15 & 28,92 & & 34,33 & \\
\hline Regiões & 1970 & 1980 & 1990 & 2000 & 2009 & Média das & Diferença da \\
\hline Ásia do Leste e Pacífico & 41,55 & 41,23 & 38,86 & 34,29 & & 38,98 & 4,65 \\
União Europeia & 40,76 & 37,15 & 33,23 & 27,96 & 23,87 & 32,59 & $-1,74$ \\
América Latina e Caribe & 36,04 & 38,84 & 35,71 & 29,91 & 30,61 & 34,22 & $-0,11$ \\
Ásia do Sul & 20,97 & 24,39 & 26,12 & 25,79 & 26,79 & 24,81 & $-9,52$ \\
África Subsaariana & 31,22 & 37,81 & 32,13 & 29,46 & 29,71 & 32,06 & $-2,27$ \\
Mundo & 38,17 & 37,09 & 33,15 & 28,92 & & 34,33 & \\
\hline Fonte:WDia & & & & & \\
\hline
\end{tabular}

Fonte: WDI, 2011.

\footnotetext{
${ }^{4} \mathrm{O}$ valor adicionado à indústria (VAIND) se refere ao produto líquido da indústria geral depois de excluídos os insumos intermediários. Neste caso, a indústria geral inclui a indústria extrativa, de transformação, construção, eletricidade, água e gás. Corresponde às divisões 10-45 da classificação ISIC (International Standard Industrial Classification), revisão 3.
} 
Tabela 3: Valor Adicionado do Setor Manufatureiro - VAMANUF (\% do PIB)

\begin{tabular}{lccccccc}
\hline Países & 1970 & 1980 & 1990 & 2000 & 2009 & $\begin{array}{c}\text { Média das } \\
\text { Décadas }\end{array}$ & $\begin{array}{c}\text { Diferença da } \\
\text { Média Mundial }\end{array}$ \\
\hline Argentina & 31,54 & 29,48 & 26,79 & 17,52 & 21,20 & 25,31 & 3,11 \\
Brasil & 29,32 & 33,49 & & 17,22 & 15,81 & 23,96 & 1,76 \\
Chile & 25,88 & 21,52 & 19,57 & 19,46 & 12,72 & 19,83 & $-2,36$ \\
China & 33,75 & 40,23 & 32,66 & 32,12 & 33,92 & 34,54 & 12,34 \\
Índia & 14,16 & 16,72 & 16,70 & 15,60 & 14,76 & 15,59 & $-6,61$ \\
Coreia do Sul & 17,79 & 24,45 & 27,26 & 28,26 & 27,74 & 25,10 & 2,90 \\
México & 23,15 & 22,26 & 20,80 & 20,31 & 17,22 & 20,75 & $-1,44$ \\
Estados Unidos & 26,65 & 22,77 & 19,42 & 16,71 & & 21,39 & $-0,81$ \\
Mundo & & 25,14 & 22,27 & 19,17 & & 22,19 & \\
\hline Regiões & 1970 & 1980 & 1990 & 2000 & 2009 & Média das & Diferença da \\
\hline Ásia do Leste e Pacífico & & 29,53 & 26,78 & 23,46 & & 26,59 & Média Mundial \\
União Europeia & & & & 19,47 & 14,67 & 17,07 & $-5,40$ \\
América Latina e Caribe & 25,69 & 26,84 & & 18,63 & 16,77 & 21,98 & $-0,21$ \\
Ásia do Sul & 14,36 & 16,31 & 16,32 & 15,44 & 15,28 & 15,54 & $-6,65$ \\
África Subsaariana & 17,91 & 16,59 & 17,61 & 14,90 & 12,73 & 15,95 & $-6,25$ \\
Mundo & & 25,14 & 22,27 & 19,17 & & 22,19 & \\
\hline Fonte:WDI & & & & & & &
\end{tabular}

Fonte: WDI, 2011.

A Tabela 3 sistematiza os dados referentes ao valor adicionado do setor manufatureiro $\left(\right.$ VAMANUF) ${ }^{5}$ em relação ao PIB e, assim como na tabela anterior, o destaque entre as economias selecionadas é a China, com média de 34,54\% no período, valor este bem acima da média mundial de $22,19 \%$, seguido da Argentina $(25,31 \%)$ e da Coreia do Sul $(25,10 \%)$, enquanto Índia e Chile tiveram as médias mais baixas. Quanto às regiões, os indicadores de VAMANUF revelam que apenas a Ásia do Leste e Pacífico teve desempenho acima da média mundial, enquanto Ásia do Sul, União Europeia e África Subsaariana ficaram bem abaixo do desempenho mundial. A interpretação final é que a China e Ásia do Leste e Pacífico podem ser considerados como outliers entre os países e regiões analisados.

\footnotetext{
${ }^{5} \mathrm{O}$ valor adicionado à manufatura (VAMANUF) se refere ao produto líquido da indústria de transformação depois de excluídos os insumos intermediários. Corresponde às divisões 15-37 da classificação ISIC (International Standard Industrial Classification), revisão 3.
} 
Tabela 4: Emprego Industrial (\% do Emprego Total)

\begin{tabular}{|c|c|c|c|c|c|c|c|}
\hline Países & 1991 & 1995 & 2000 & 2005 & 2009 & Média & $\begin{array}{l}\text { Diferença da } \\
\text { Média Mundial }\end{array}$ \\
\hline Argentina & 32,40 & 27,30 & 22,70 & 23,50 & 23,10 & 25,80 & 3,89 \\
\hline Brasil & & 19,60 & 21,20 & 21,40 & 22,10 & 21,08 & $-0,83$ \\
\hline Chile & 26,30 & 26,10 & 23,40 & 23,00 & 23,20 & 24,40 & 2,49 \\
\hline China & 21,40 & 23,00 & 22,50 & 23,80 & & 22,68 & 0,77 \\
\hline Índia & & & 16,10 & 19,00 & & 17,55 & $-4,36$ \\
\hline Coreia do Sul & 36,00 & 33,30 & 28,10 & 26,80 & & 31,05 & 9,14 \\
\hline México & 23,10 & 21,50 & 26,90 & 25,70 & 23,90 & 24,22 & 2,31 \\
\hline Estados Unidos & 25,50 & 24,30 & 23,20 & 20,60 & & 23,40 & 1,49 \\
\hline Mundo & & & 21,65 & 22,16 & & 21,91 & \\
\hline Regiões & 1991 & 1995 & 2000 & 2005 & 2009 & Média & $\begin{array}{l}\text { Diferença da } \\
\text { Média Mundial }\end{array}$ \\
\hline Ásia do Leste e Pacífico & 21,86 & 23,32 & 22,01 & 23,24 & & 22,61 & 0,70 \\
\hline União Europeia & 33,83 & 31,05 & 29,28 & 27,51 & 25,87 & 29,51 & 7,60 \\
\hline América Latina e Caribe & & 22,41 & 22,64 & 23,03 & 22,33 & 22,60 & 0,69 \\
\hline Ásia do Sul & & & 15,57 & 18,68 & & 17,13 & $-4,78$ \\
\hline Mundo & & & 21,65 & 22,16 & & 21,91 & \\
\hline
\end{tabular}

Fonte: WDI, 2011.

Nota: Os dados de Emprego Industrial não estão disponíveis para a África Subsaariana.

O último indicador a ser analisado na Tabela 4, para o período de 1991 a 2009 , é a participação do emprego industrial como porcentagem do emprego total. Neste caso, a Coreia do Sul é o país com maior participação (31,05\%), e os países da América Latina, com exceção feita ao Brasil, têm participação acima da média mundial $(21,91 \%)$, enquanto a Índia é o país com menor valor para este indicador. O caso da China, que pode ser considerado como um destaque em todas as tabelas e indicadores anteriormente analisados, não se verifica quanto ao indicador de emprego industrial, já que na média do período seu valor $(22,68 \%)$ encontra-se próximo ao da média mundial $(21,91 \%)$. A União Europeia é claramente a região com maior participação do emprego industrial, o que se justifica em função do caráter histórico de precedência no desenvolvimento do setor industrial quando comparado às demais regiões analisadas, sendo que a América Latina e Caribe possui indicador de emprego industrial próximo à média mundial, enquanto a Ásia do Sul tem menor valor para este indicador.

As lições que podem ser apreendidas a partir da análise dos indicadores do setor industrial / manufatureiro, tanto em termos de valor adicionado quanto de emprego, é que ao longo das últimas décadas há uma tendência de destaque para países como China e Coreia do Sul e que se revela também presente na análise das regiões, já que estes são integrantes da Ásia do Leste e Pacífico. Uma tendência oposta, no sentido de indicadores relativos mais frágeis, está associada aos países da América 
Latina analisados (Brasil incluído), cujo panorama releva quanto à nossa variável de interesse (crescimento econômico) um pior desempenho destas economias quando comparados com a Ásia e alguns de seus países (China, Índia e Coreia do Sul).

\section{SÍNTESE DOS RESULTADOS ECONOMÉTRICOS}

O objetivo central da investigação econométrica dos modelos de crescimento neste trabalho é avaliar o sinal e a significância estatística dos coeficientes das variáveis participação da indústria no PIB (INDÚSTRIA / PIB), da participação do setor manufatureiro no PIB (MANUFATURA / PIB), e do emprego da indústria em relação ao emprego total da economia (EMPREGO INDUSTRIAL). Com isso, pretende-se avaliar a importância da indústria e do emprego industrial no crescimento econômico de longo prazo. Os modelos estimados incluem ainda outras variáveis ${ }^{6}$ consagradas pela literatura empírica de crescimento, como o nível de renda per capita (LPIBINICIAL), a inflação (LINF), escolaridade secundária (LEDUC), gastos do governo (LGOV), qualidade institucional (LEI e ORDEM) e o desalinhamento da taxa de câmbio real (DESALINHAMENTO) ${ }^{7}$.

A variável nível de renda per capita (LPIBINICIAL) é incluída para testar a hipótese de convergência de renda, ou seja, de que quanto maior o PIB per capita inicial, menor a sua taxa de crescimento. A variável inflação (LINF) é incluída entre as variáveis explanatórias como proxy para estabilidade macroeconômica. Acredita-se que o aumento da taxa de inflação tem impacto negativo sobre o crescimento econômico. A variável gastos do governo (LGOV) é usualmente incluída em estudos empíricos como proxy para o tamanho do governo na economia ou como disciplina fiscal, esperando-se que o coeficiente associado seja negativo. A variável escolaridade secundária (LEDUC) é inserida no modelo para captar o nível de escolaridade da população, servindo como proxy para o capital humano. Espera-se que o aumento na escolaridade secundária da população tenha efeito positivo sobre o crescimento econômico. A variável LEI e ORDEM é incluída no modelo como proxy de qualidade institucional, e acredita-se que o coeficiente associado seja positivo. O desalinhamento da taxa de câmbio real (DESALINHAMENTO) é incluído com o objetivo de verificar que a taxa de câmbio subvalorizada (sobrevalorizada) estimula (reduz) o crescimento econômico (Barro \& Sala-i-Martin, 2004; Rodrik, 2008; Rodrik, 2009).

As estimações dos modelos de crescimento utilizam dados de média a cada cinco anos para o período de 1970 a 2009, com exceção do PIB inicial onde se

\footnotetext{
${ }^{6}$ Ver Tabela 1A do Apêndice para a lista de variáveis, nomenclatura e fonte dos dados.

${ }^{7}$ A inclusão da variável DESALINHAMENTO foi obtida através da diferença entre a taxa de câmbio real corrente e seu valor de equilíbrio obtido através da estimação por Efeitos Fixos considerando o chamado efeito Balassa-Samuelson (variável RGDPCH da base de dados Penn World Table 7.1) e as dummies temporais, ou seja, seguindo o mesmo procedimento utilizado por Rodrik (2008). O coeficiente estimado para RGDPCH foi de - 0,157 (significativo a 1\%), sendo que o coeficiente estimado por Rodrik (2008) para uma amostra de países distinta e com período de análise também distinto foi de - 0,24.
} 
utilizou o ano inicial do quinquênio. Todas as estimações são para modelos System GMM Two-Step com erros robustos e lidam com o problema da proliferação dos instrumentos ${ }^{8}$. Além da estimação dos coeficientes, foram realizados também os testes de ausência de autocorrelação de segunda ordem, $\operatorname{AR}(2)$, o teste de Hansen para as restrições sobreidenficadoras (validade dos instrumentos) e o teste para a exogeneidade dos instrumentos (Hansen-Difference) ${ }^{9}$.

Foram estimados quatro modelos para cada uma das amostras, onde as variáveis de interesses (INDUSTRIAPIB, MANUFATURAPIB e EMPREGO INDUSTRIAL) foram utilizadas individualmente em cada um dos três modelos onde a variável dependente é a taxa de crescimento do PIB real per capita, com as seguintes especificações para as variáveis explicativas:

A - Modelo com INDÚSTRIA / PIB

Modelo 1: CRESCIMENTO ${ }_{t-1}$; LPIBINICIAL; INDÚSTRIA / PIB

Modelo 2: CRESCIMENTO ${ }_{t-1}$;PIBINICIAL;LEDUC;LGOV;LINF;INDÚSTRIA/ PIB

Modelo 3: CRESCIMENTO ${ }_{t-1}$ :LPIBINICIAL;LEDUC;LGOV;LINF;LEIeORDEM;INDÚSTRIA/PIB

Modelo 4: CRESCIMENTO ; LPIBINICIAL;LEDUC;LGOV;LINF;LEIIORDEM;INDÚSTRIA/ PIB;DESALINHAMENTO

B - Modelo com MANUFATURA / PIB

Modelo 1: CRESCIMENTO ${ }_{t-1}$;PIBINICIAL;MANUFATURA/PIB

Modelo 2: CRESCIMENTO ${ }_{t-1}$ LPIBINICIAL;LEDUC;LGOV;LINF;MANUFATURA/PIB

Modelo 3: CRESCIMENTO ;LPIBINICIAL;LEDUC;LGOV;LINF;LEIOORDEM;MANUFATURA/PIB

Modelo 4: CRESCIMENTO; ${ }_{t-1}$ LPIBINICIAL;LEDUC;LGOV;LINF;LELOORDEM;MANUFATURA/ PIB;DESALINHAMENTO

C - Modelo com EMPREGO INDUSTRIAL

Modelo 1: CRESCIMENTO ${ }_{t-1}$; LPIBINICIAL;EMPREGO INDUSTRIAL

\footnotetext{
${ }^{8}$ As estimações foram desenvolvidas com a utilização da rotina XTABOND2 (Roodman, 2009a) e utilizaram-se os comandos laglimits ou collapse para o Stata 11, sendo que a preferência foi da utilização do comando laglimits, pois este não impõe uma menor redução no número de instrumentos quando comparado ao collapse, sendo que a utilização deste último foi adotada quando mesmo com o comando laglimits, o número de instrumentos continuou elevado em relação ao número de países, o que está associado a uma convergência da probabilidade do teste Hansen-Difference para 1.000 (Roodman, 2009b). Windmeijer (2005) faz uma correção em amostras finitas na matriz de covariância de forma a tornar as estimações Two-Step com erros robustos mais eficiente.

${ }^{9}$ A hipótese nula do teste AR(2) é de ausência de autocorrelação de segunda ordem, a do teste Hansen é de validade dos instrumentos, ou seja, as restrições sobreindentificadoras são válidas, e de exogeneidade dos instrumentos no teste Hansen-Difference.
} 
Modelo 2: CRESCIMENTO $_{t-1}$;LPIBINICIAL;LEDUC;LGOV;LINF;EMPREGO INDUSTRIAL

Modelo 3: CRESCIMENTO ${ }_{t-1}$ LPIBINICIAL;LEDUC;LGOV;LINF;LEIeORDEM;EMPREGO INDUSTRIAL

Modelo 4: CRESCIMENTO ${ }_{t-1}$ :LPIBINICIAL;LEDUC;LGOV;LINF;LEIeORDEM;EMPREGO INDUSTRIAL;DESALINHAMENTO

Tabela 5: Modelos de Crescimento - Coeficientes Estimados para a Participação da Indústria no PIB, Participação do Setor Manufatureiro no PIB e Participação do Emprego Industrial no Emprego Total

\begin{tabular}{|c|c|c|c|c|c|c|c|c|}
\hline \multirow[b]{2}{*}{ Modelos } & \multicolumn{4}{|c|}{ Amostra Completa } & \multicolumn{4}{|c|}{$\begin{array}{l}\text { Economias Emergentes } \\
\text { e em Desenvolvimento }\end{array}$} \\
\hline & 1 & 2 & 3 & 4 & 1 & 2 & 3 & 4 \\
\hline INDÚSTRIA / PIB & $0,1571 * * *$ & $0,0962 * * *$ & $0,1077 * * *$ & $0,163 * * *$ & $0,1245^{* * *}$ & $0,1129 * *$ & $0,1369 * * *$ & $0,133^{* *}$ \\
\hline Erros Robustos & $(0,352)$ & $(0,3282)$ & $(0,0321)$ & $(0,054)$ & $(0,0384)$ & $(0,0671)$ & $(0,0484)$ & $(0,052)$ \\
\hline$A R(2)$ & 0,370 & 0,360 & 0,631 & 0,822 & 0,323 & 0,508 & 0,629 & 0,971 \\
\hline Hansen & 0,077 & 0,354 & 0,303 & 0,155 & 0,396 & 0,193 & 0,498 & 0,745 \\
\hline Hansen-Diff & 0,842 & 0,978 & 0,921 & 0,574 & 0,884 & 0,088 & 0,366 & 0,543 \\
\hline Número de Países & 80 & 77 & 77 & 76 & 63 & 60 & 60 & 60 \\
\hline Número de Instrumentos & 60 & 80 & 80 & 63 & 60 & 50 & 56 & 63 \\
\hline MANUFATURA / PIB & $0,1545^{* * *}$ & $0,1259 * * *$ & $0,1376 * * *$ & $0,205^{* * *}$ & $0,1046^{* *}$ & 0,1104 & $0,1837^{* * *}$ & $0,133^{*}$ \\
\hline Erros Robustos & $(0,0458)$ & $(0,412)$ & $(0,0345)$ & $(0,064)$ & $(0,0459)$ & $(0,0953)$ & $(0,0754)$ & $(0,077)$ \\
\hline$A R(2)$ & 0,147 & 0,258 & 0,568 & 0,762 & 0,157 & 0,402 & 0,823 & 0,653 \\
\hline Hansen & 0,039 & 0,412 & 0,425 & 0,125 & 0,302 & 0,435 & 0,537 & 0,370 \\
\hline Hansen-Diff & 0,484 & 0,957 & 0,919 & 0,678 & 0,341 & 0,493 & 0,189 & 0,370 \\
\hline Número de Países & 80 & 77 & 77 & 76 & 63 & 60 & 60 & 60 \\
\hline Número de Instrumentos & 60 & 80 & 80 & 63 & 60 & 50 & 56 & 63 \\
\hline EMPREGO INDUSTRIAL & 0,0955 & $0,1635^{* * *}$ & $0,1653^{* * *}$ & $0,188^{* * *}$ & $-0,0134$ & $0,2595^{* *}$ & $0,2020 *$ & 0,156 \\
\hline Erros Robustos & $(0,0718)$ & $(0,0527)$ & $(0,0491)$ & $(0,048)$ & $(0,099)$ & $(0,0971)$ & $(0,1062)$ & $(0,099)$ \\
\hline$A R(2)$ & 0,773 & 0,958 & 0,901 & 0,863 & 0,762 & 0,958 & 0,931 & 0,928 \\
\hline Hansen & 0,315 & 0,278 & 0,380 & 0,831 & 0,570 & 0,251 & 0,459 & 0,996 \\
\hline Hansen-Diff & 0,580 & 0,747 & 0,899 & 0,954 & 0,581 & 0,300 & 0,187 & 0,999 \\
\hline Número de Países & 79 & 76 & 76 & 75 & 62 & 59 & 59 & 59 \\
\hline Número de Instrumentos & 49 & 69 & 77 & 88 & 49 & 47 & 54 & 88 \\
\hline
\end{tabular}

Notas: Erro-padrão em parênteses.

$*^{*}{ }^{*} e^{* * *}$ indicam significância estatística a 10\%, 5\% e 1\%, respectivamente.

Todas as estimações são por System GMM Two-Step.

Todos os modelos incluem dummies de tempo.

Os modelos estimados controlam para o excesso de instrumentos - Comandos Collapse ou Laglimits - Stata 11.

Os resultados das estimações dos modelos de crescimento encontram-se sistematizados na Tabela 5. A estimação dos modelos de crescimento foi dividida entre amostra completa ( 82 países) e economias emergentes e em desenvolvimento (63 países) no intuito de comparar a significância estatística, o sinal e a magnitude dos coeficientes estimados entre as duas amostras. 
Os resultados da Tabela 5 indicam que os coeficientes estimados para a variável INDÚSTRIA / PIB foram positivos e estatisticamente significativos independentemente do modelo especificado ou da amostra, com o menor valor de 0,096 e o maior valor de 0,163 , indicando que uma elevação de $10 \%$ na participação da indústria no PIB tem um impacto entre $0,96 \%$ e $1,63 \%$ na taxa de crescimento do PIB real per capita a cada 5 anos, representando um aumento médio anual entre $0,19 \%$ e $0,32 \%$ na taxa de crescimento.

Os coeficientes estimados da variável MANUFATURA / PIB foram positivos e estatisticamente significativos, exceção feita ao modelo 2 na amostra das economias emergentes e em desenvolvimento, sendo que os coeficientes estimados variaram entre 0,104 e 0,205 , indicando que uma elevação de $10 \%$ na participação do setor manufatureiro no PIB tem um impacto entre $1 \%$ e $2 \%$ na taxa de crescimento do PIB real per capita a cada 5 anos, o que resulta em um aumento médio anual na taxa de crescimento entre $0,2 \%$ e $0,4 \%{ }^{10}$.

Por fim, os resultados das estimações dos coeficientes da variável EMPREGO INDUSTRIAL indicam que estes foram positivos para todos os modelos com exceção do modelo 1 para as economias emergentes e em desenvolvimento, enquanto a significância estatística foi observada em todos os modelos com exceção do modelo 1 nas duas amostras e do modelo 4 para as economias emergentes e em desenvolvimento. Os coeficientes estatisticamente significativos variam entre 0,163 e 0,259 , indicando que uma elevação de $10 \%$ na participação do emprego industrial no total do emprego tem um impacto entre $1,63 \%$ e $2,59 \%$ na taxa de crescimento do PIB real per capita a cada 5 anos, o que está associado a um aumento médio anual na taxa de crescimento entre $0,32 \%$ e $0,51 \%$.

A análise dos testes AR(2), Hansen e Hansen-Diff utilizando o nível de significância de 5\% revela, respectivamente, que os diversos modelos estimados não têm problema de correlação de segunda ordem, os instrumentos são válidos com exceção do modelo 1 da Tabela 5, para a especificação que inclui a variável MANUFATURA / PIB na amostra completa, e que os instrumentos são exógenos.

A lição geral a ser assimilada com a estimação dos modelos de crescimento é que os coeficientes estimados para as variáveis de interesse (INDÚSTRIA / PIB, MANUFATURA / PIB e EMPREGO INDUSTRIAL / EMPREGO TOTAL) são positivos e estatisticamente significativos na maioria dos modelos especificados e amostras utilizadas, indicando que políticas que visem ampliar a participação da indústria (setor manufatureiro) no PIB e do emprego industrial no emprego total estimulam o crescimento de longo prazo $^{11}$.

\footnotetext{
${ }^{10}$ Cabe destacar que o desalinhamento cambial é estatisticamente significativo para o modelo que inclui a participação do setor manufatureiro no PIB (MANUFATURA / PIB), como revelam as estimações da Tabela 5, porém o mesmo não se revelou estatisticamente significativo nas demais estimações. Além disso, os coeficientes estimados são positivos nos modelos que incluem a participação da indústria no PIB e da manufatura no PIB, indicando que taxas de câmbio subvalorizadas (sobrevalorizadas) estimulam (reduzem) o crescimento econômico.
}

${ }^{11}$ Observa-se que a participação do emprego industrial (quando a variável se mostra estatisticamente 


\section{CONSIDERAÇÕES FINAIS}

A investigação empírica com base na estimação de modelos de crescimento em painel (System GMM) foi conduzida em três especificações distintas para se avaliar a relevância e o impacto das variáveis participação da indústria no PIB, participação do setor manufatureiro no PIB e do emprego industrial no emprego total.

Os resultados da estimação econométrica dos modelos de crescimento permitem assimilar como lição geral a importância para o crescimento econômico das variáveis INDÚSTRIA / PIB, MANUFATURA / PIB e EMPREGO INDUSTRIAL / EMPREGO TOTAL, já que os coeficientes estimados foram, na grande maioria dos casos, positivos e estatisticamente significativos. Além disso, pode-se argumentar que tais coeficientes são maiores para as economias emergentes e em desenvolvimento, sugerindo que estas economias têm benefícios adicionais em termos de crescimento de longo prazo ao adotarem políticas que estimulem a participação do setor industrial (e manufatureiro) no PIB e do emprego industrial no emprego total.

A elaboração deste trabalho sobre a importância da indústria para o desenvolvimento e o crescimento econômico revela a existência de importantes canais através dos quais uma dinâmica vigorosa deste setor, seja em termos de participação no PIB ou de emprego, pode contribuir para uma melhoria no nível de desenvolvimento e crescimento econômico. Esta é uma questão que vem sendo debatida por diversos autores da literatura, com repercussões importantes para a economia brasileira no período mais recente, onde o debate sobre a desindustrialização tem tido um destaque tanto no meio acadêmico quanto político.

\section{REFERÊNCIAS BIBLIOGRÁFICAS}

Abelles, M.; Rivas, D. (2010). “Growth versus development: different patterns of industrial growth in Latin America during the "boom'years". CEPAL: United Nations.

Arellano, M.; Bond, S. (1991) "Some Tests of Specification for Panel Data: Monte Carlo Evidence and an Application to Employment Equations," Review of Economic Studies, Blackwell Publishing, vol. 58(2), 277-97.

significante), em geral, tem maiores impactos (maior magnitude dos coeficientes) nos resultados de crescimento de longo prazo do que os indicadores manufatura/PIB e indústria/PIB, especialmente para a amostra de países emergentes. Tais resultados aparentemente não se coadunam com as evidências obtidas por Tregenna (2008). Para a autora, a participação do emprego na manufatura não deve ser analisada em separado da participação da manufatura no PIB para se constatar desindustrialização, uma vez que os aumentos de produtividade do trabalho podem levar a uma redução da participação do emprego industrial sem que se verifique uma queda da participação da atividade industrial na geração do produto. As evidências obtidas no presente artigo podem estar atreladas ao fato de que os países emergentes contam com menores níveis de produtividade do trabalho em comparação com os países avançados. Ademais, seus processos produtivos envolvem maior utilização de tecnologias intensivas em trabalho. Neste contexto, uma maior participação do emprego tem um efeito relativo importante para se alcançar taxas de crescimento do PIB maiores no longo prazo. 
Arellano, M.; Bover, O. (1995) "Another look at the instrumental variable estimation of error-components models," Journal of Econometrics, Vol. 68(1), 29-51.

Baer, W. (1972) "Import Substitution and Industrialization in Latin America: Experiences and Interpretations." Latin American Research Review, Vol. 7, No. 1, 95-122.

Barro, R.J.; Sala-i-Martin, X. (2004) Economic Growth. The MIT Press, $2^{\text {nd }}$ d.

Berg, A; Miao, Y. (2010) “The Real Exchange Rate and Growth Revisited: The Washington Consensus Strikes Back?” IMF Working Paper 10/58. Washington: International Monetary Fund, 2010.

Bresser-Pereira, L. C.; Marconi, N. (2008) “Existe Doença Holandesa no Brasil?” IV Fórum de Economia da Fundação Getúlio Vargas. Março. Disponível em: http://www.bresserpereira.org.br. Acesso em Outubro de 2008.

Blundell, R; Bond, S. (1998) "Initial conditions and moment restrictions in dynamic panel data models." Journal of Econometrics, 87(1), 115-143.

Cepal - Comissão Econômica para América Latina e Caribe (2008). Progreso técnico y cambio estructural en América Latina. Nações Unidas.

Chenery, H. B. (1960) "Patterns of Industrial Growth.” The American Economic Review, Vol. 50, No. 4, 624-654.

Chenery, H. B.; Watanabe, T. (1958) “International Comparisons of the Structure of Production,” Econometrica, Vol. 26, 487-521.

De Long, J.B.; Summers, L. H. (1991) “Equipment Investment and Economic Growth.” Quarterly Journal of Economics, Vol.106, No.2, 445-502.

Gala, P. (2008) "Real Exchange Rate Levels and Economic Development: Theoretical Analysis and Econometric Evidence." Cambridge Journal of Economics 32:273-288.

Kaldor, N. (1957). “A Model of Economic Growth.” The Economic Journal, 67 (268), 591-624.

Kaldor, N. (1966). Causes of the Slow Rate of Economic Growth of the United Kingdom: an Inaugural Lecture. Cambridge: Cambridge University Press.

Libânio, G.; Moro, S. (2009) "Manufacturing Industry and Economic Growth in Latin America: A Kaldorian Approach". Anais do XXXVII Encontro Nacional de Economia, Foz do Iguaçu/PR, Dezembro. Disponível em: http://www.anpec.org.br/encontro2009/inscricao.on/arquivos/000-98e6915698ae97aca03d8e866339ae4e.pdf. Acesso em Janeiro de 2012.

Oreiro, J. L.; Feijó, C. A. (2010) "Desindustrialização: Conceituação, Causas, Efeitos e o Caso Brasileiro." Revista de Economia Política, Vol. 30 (2), 219-232.

Pieper, U. (1998). "Deindustrialization and the Social and Economic Sustainability Nexus in Developing Countries: Cross-Country Evidence on Productivity and Employment." Center for Economic Policy Analysis Working Paper, 10, 1-47.

Rodrik, D. (2008) “The Real Exchange Rate and Economic Growth.” Brookings Papers on Economic Activity, 2:365-412.

Rodrik, D. (2009) “Growth after the Crisis". Harvard Kennedy School. Cambridge, MA 02138. Paper prepared for Commission on Growth and Development, Revised. Disponível em: http://www. growthcommission.org/storage/cgdev/documents/financial_crisis/rodrikafterthecrisis.pdf. Acesso em Janeiro de 2012.

Roodman, D. (2009a) “How to do xtabond2: An Introduction to Difference and System GMM in

Stata," Stata Journal, 9 (1), 86-136.

Roodman, D. (2009b) "A Note on the Theme of Too Many Instruments." Oxford Bulletin of Economics and Statistics 71 (1), 135-158.

Sampaio, D. P.; Pereira, V. V. (2009) “Doença Holandesa No Brasil: Uma Sugestão De Análise Conceitual Comparada”. XIV Encontro Nacional de Economia Política. São Paulo, Junho.

Solow, R. M. (1956) "A Contribution to the Theory of Economic Growth.” Quarterly Journal of Economics.Vol. 70 (1), 65-94.

Tregenna, F. (2008) "Characterising deindustrialization: An analysis of changes in manufacturing employment and output internationally". Cambridge Journal of Economics, 33, 433-466.

Vieira, F.V., MacDonald, R. (2012) "A Panel Data Investigation of Real Exchange Rate Misalignment and Growth.” EstudosEconômicos, 42, 433 - 456.

WDI - World Development Indicators.Banco Mundial, 2011.

Windmeijer, F. (2005) "A Finite Sample Correction for the Variance of Linear Efficient Two-step GMM Estimators." Journal of Econometrics, Vol. 126, 25-51. 


\section{APÊNDICE}

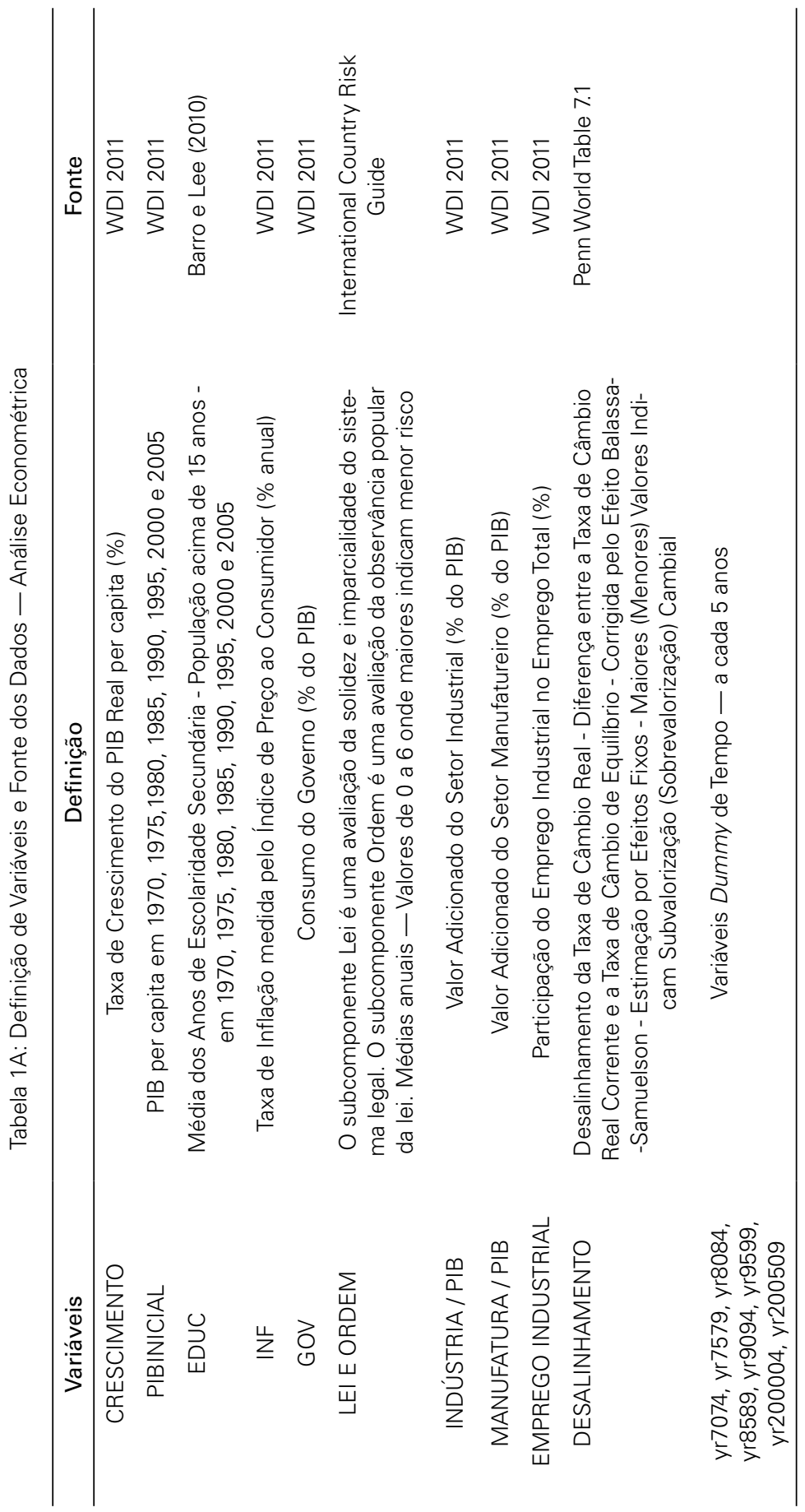

